\title{
Positive Change in Self-esteem through Linguistic and Psychological Training among Iranian Kurdish University Students*
}

\author{
Tahereh Ahmadipour \\ Language and Linguistics Department, Vali-e-Asr University, Rafsanjan, Iran \\ Email: ahmadipour@vru.ac.ir \\ Somayeh Hadad Ranjbar \\ Psychological Department, Vali-e-Asr University, Rafsanjan, Iran \\ Email: s.hadad@vru.ac.ir
}

\begin{abstract}
This paper reports an action research into how teaching and researching program for Iranian Kurdish students could positively change the state of their self-esteem. The study aimed to implement and evaluate the teaching of two side-by-side courses: Persian pronunciation and life skill teaching programs, as well as to identify the benefits for the students. Data collected in different ways: reflective reports, focused interviews, diaries of the participants, and observation analysis of the researchers and the observers. Findings identified the success of the teaching program and revealed substantial benefits for the students. Although the project had, some limitations but the findings provided support for the hypothesis. It is suggested that the collaboration between psychological and phonological teaching courses offers a potential model for developing healthy self-esteem to similar students.
\end{abstract}

Index Terms - action research, self-esteem, positive change, Kurdish students, Persian pronunciation teaching, life skills teaching

\section{INTRODUCTION}

Freshmen face a variety of challenges while they enter the academic environments. Among them, the ethnolinguistic minorities such as Kurdish students showed they involve even some more problems. In this new environment, because they are not so accurate or fluent in Persian, as the only official and national language, in class participation and some other social and personal relations, they show poor self-image and low confidence little by little. This could result in their social withdrawal, lack of social skills and self-confidence, less social conformity, treating themselves badly and so on that are the indicators of unhealthy self-esteem. Some psychologists (Allport, 1955, Maslow, 1987, Rogers, 1961) regard self-esteem as universal and essential need for human being.

\section{SELF-eSTEEM LiterATURE}

The benefits associated with having high self-esteem, as a part of self-concept has been the subject of hundreds of studies (Rosenberg, 1972, 1979). Researchers argued that high self-esteem because of positive outcomes would be beneficial for both individual and society as a whole (Porter \& Washington, 1993). A large and growing body of literature have been produced from the time that Rosenberg and some other social learning theorists such as Branden (1960s) for the first times defined self-esteem as "... the experience of being competent to cope with the basic challenges of life and being worthy of happiness"(branden, 1969). Branden defined self-esteem as the sum of "selfconfidence" (a feeling of personal capacity) and "self-respect" (a feeling of personal worth). For him the primary properties of self-esteem to see it as a basic human need, i.e., "...it makes an essential contribution to the life process". The levels of self-esteem also for Branden involves three main items as levels of : having a high self-esteem for him means to feel confidently capable for life; but not feeling ready for life or feeling wrong as a person is the symptoms of low self-esteem; and branden deemed to have a middle ground self-esteem that is identified as an item between the two.

Many early theories suggested that self-esteem is a basic human need or motivation. American psychologist Maslow for example, included self-esteem in his hierarchy of needs and as two different forms of esteem: the need for respect from others and the need for self-respect, or inner self-esteem (1987). Some researchers (Bonet, 1997; Gill, 1980) suggested some characteristics as indicators for those who have positive or negative self-esteem. Those with positive and healthy self esteem show some features such as firmly believing in certain values and principles and defending for them as well as being able to modify them; trusting themselves and acting based on their own judgment with no guilty

\footnotetext{
* The research reported in this article was supported by Vali-e-Asr University of Rafsanjan grant to Tahereh Ahmadipour.
} 
feeling; living in the present without subject to be affected from past and future; not asking others' help but trusting in himself to solve the problems. On the other hand those with low self esteem are deemed to show some of the following symptoms: dissatisfying with themselves; very sensitive to criticism; very fearful of making a mistake; unwilling to say no; self-demanded to do perfectly; condemning indefinitely and never reaching full forgiveness; feeling bad and irritability about everything; being pessimistic about everything (Bonet, 1997, Gill, 1980).

A growing body of research has also documented the significance of self-esteem as a key factor in the students' school success and in relationships with their peers, and in their later success in life. A vast majority of the published works have focused on the necessity of strategies to increase self-esteem in schools, implemented programs aimed at boosting student's self-esteem in the hopes of reducing problems at schools in previous century (Mecca, Smelser \& Vasconcellos, 1989, Dawes, 1994). But recent researches (Baumeister et al., 2003, Baumeister et al., 2005) shows that" inflating" self-esteem by itself can actually decrease grades. The results of these researches did not signify that lifting self-esteem raise academic performance. However, some newer investigations reported that it is only when students engage in personally meaningful endeavors for which they can be justifiably proud that self-confidence grows, and it is this growing self-assurance that in turn triggers further achievement. Howerver Baumeister, et al. (2003) believed that high self-esteem correlates highly with "self-reported happiness", it is not clear which, if either necessarily leads to the other and based on some studied to forgiveness (Eaton et al., 2006).

For students of minorities seemingly the issue of self-esteem has somehow different and needs more challenges (Toulouse n.d., Hilberg\&Tharp, 2002, Kanu, 2002, Swanson, 2003). Some researchers argued that the multicultural environment has a powerful influence on "building up or tearing down" self-esteem. They believed that the culturally different student might have developed feeling of inadequacy or a weak self-image. The researchers also enumerated some cultural differences which impede the learning process because of low self-esteem including Language barriers (King, 1997).

Crocker and Park (2004) suggested more challenging attitude to the importance of self-esteem. They particularly interested in how people pursue self-esteem by trying to prove or demonstrate that they have worth and value. They argued that the objective benefits of high self-esteem are small and limited. They cited the Baumeister et al.'s review (2003), concluded, "High self-esteem produces pleasant feelings and enhanced initiative, but does not cause high academic achievement, good job performance, or leadership". Although the authors argued the long-term costs of pursing self-esteem, the ways of avoiding its costs have been discussed as well. Moreover some researchers recently propose that the importance of self-esteem lies more in how people strive for it rather than whether it is high or low (Baumeister, et al., 2003, Crocker \& Park, 2004).Some other psychologists such as Dubois and Flay (2004) theoretically indicated that both level and pursuit of self-esteem could be influential in shaping overall health and wellbeing.

\section{RESEARCH DESIGN AND METHOD}

This study is a part of a larger project that aims to examine the possibility of producing a positive change in the selfesteem of minority university students, those whose native language is different from the official and national language (Persian) on an action research project. This decided to be done through the implementation of a teaching program in two fields that is linguistics (Persian pronunciation) and psychological (life skills). Therefore secondary aims for each field developed. Specifically this study addressed the following questions as secondary purposes: Does Persian pronunciation training have a positive effect on the self-esteem of Kurdish students? Does living skills training have a positive effect on the self-esteem of Kurdish students?

Sources and the Identification of the problem

To identify the problem we had different sources. The researchers' long experiences as instructors and advisors for years contacting with such students and their colleagues reports about the issue served as the first source. Most of the non-Persian new students sat at last rows or somewhere far from the eye contact of the teacher, they rarely ask questions or tend to volunteer in class participation. If they force to, they experience a lot of embarrassing. We concluded that these behaviors could be related to, as Branden (1969) defined, their feeling of personal capacity and a part of their selfesteem namely "self-confidence".

The second source was the students' own reflection in focused interviews about the problem. They said that they are afraid of being mocked in class by other students and they prefer not to participate in some oral activities. They asserted that while speaking Persian they just shoot the words out hurrily one after the other in order just to convey their meaning and do not find any time to think about accuracy and fluency of words and sentences. They confessed that they stressfully just release the words out to express themselves and all the time they are inconvenient about their Persian speaking. Some of them said that after speaking Persian in classes or in front of others, they become aggressive. The need for respect from others according to Maslow in one's hierarchy of needs along with the need for self-respect, or inner self-esteem (1987) cannot be meet when a person is afraid for example to be mocked.

The result of the test done through Coopersmith' questionnaire of self-esteem was the last source. The results were surprising because their self-esteem score showed to be whether low average or higher than usual. Their lie score was high. In this study, we searched for positive change and we did not aim to heighten or lessen self-esteem. Both very high and very low self-esteem can be considered disorder and destructive to the students. As Crocker and Park (2004) 
suggested, we aimed to substituting the pursuit of self-esteem with the pursuit of the goals. This meant for us that we should concentrate on some teaching courses to make the students equipped with the desired skills then ultimately resultant self-esteem boost as a welcomed side-effect would be gained, while, based on Crocker and Park, we could minimize the overall personal cost.

Based on the sources mentioned, the following facts about the selected Kurdish students, among others, were crucial: their inability to speak Persian fluently, their inability to build contact with others whose languages are different from theirs, lack of tendency to participate in group activities, their inability to control their stress specially while speaking in Persian, their strong reaction of anger and fear of being mocked by others while speaking Persian.

Context of the Study

Because in this research we looked for a "positive change", we decided to focus on action research. This practically oriented and a classroom based research method could be interesting to the students and it provided them with a tool for investigating their Persian linguistic problems as well as living skills ones through cycles of action and reflection.

We designed the action research courses for two 90-minute classes (one class for phonological and the other for life skills) per week over a 8-week semester from October to December 2011. Ten Kurdish university students in Vali-e-Asr University in Kerman Province in Iran attended the program. The course materials were extracted from four famous Persian Phonetics and phonological books and one for living skills. Some reading materials along with listening materials recorded from daily Iranian TV and radio programs. All the class sessions were planned based on lecture/ discussion format to introduce base materials and then shifted to student participation. Each step followed by instructors' observations of class participation, students 'reflective reports, group discussions, the observer instructors' observations, and the assessment of the two courses were based on these mentioned points.

Participants

The participants were Ten freshmen Kurd students (5males and 5females) volunteered to participate in the project from two universities in Kerman Provinces in south east of Iran they varied in terms of their age but the same L1 backgrounds, all studying in BA degree in different fields. They were all from the west part of the country and their Persian had a heavy shade of their native pronunciation. They all stated that they hoped the project could help them with their Persian speaking so that their relationships in the society become easier. We applied a purposive approach to sampling according to the following parameters:

- They were freshmen, in first or second semester in BA degree that for the first time enter a non-native environment.

- They had problem(s) in their self-esteem based on the evidences from our different sources.

- Their Persian pronunciation was not so intelligible or fluent.

- They were volunteered to participate the project and interested in changing their psychological and phonological situations.

Action design

The specific methodology that we used for change was a qualitative action research, designed to result in a proper change in the participants' self-esteem through two separate educational steps (phonological and psychological) that simultaneously applied for the main purpose. This method allowed us, to monitor the change process, to have reflection on, in a critical manner and where there is a need, revise their project goals, Methods and findings. It has been said that action research is small scale, contextualized, localized aimed at discovering, or monitoring changes to practice (Wallace, 2000).And as action research's features summarized by Burns" identifies and investigates problems within specific situations. It is evaluative and reflective as it aims to bring a change and improvement in practice. It is participatory as it provides for collaborative investigation by team of colleagues, practitioners and researchers. Changes in practice based on the collection of information or data that provides the impetus for change (Burns, 1999, p.34). Action research as an approach that finally results in improvement in what happens in classroom and school (Kemmis \&McTaggart,1988, p.5), we got to this insight that this research can have enough advantages for our goal over other approaches. In planning the steps for action research as Lewis (1946) as a pioneer in devising action research theories stated we should plan for spiral steps, each of which composed of special planning, action and the evaluation of the result of the action. This flexible and dynamic type of research according to Grundy (1982) has a series of overlapping cycles of planning, acting, observing and reflecting by the participants. We inspired from the idea of Grundy's three modes of action research as the minimal requirements. These modes emphasizes on the project to have a social practice subject matter capable to improvement, a spiral of cycles of four mentioned steps systematically and self-critically implemented and interrelated. Moreover, the project involves active participation (Grundy, 1982). In this project, there were two contemporary phases with eight overlapping cycles (Figure1). 


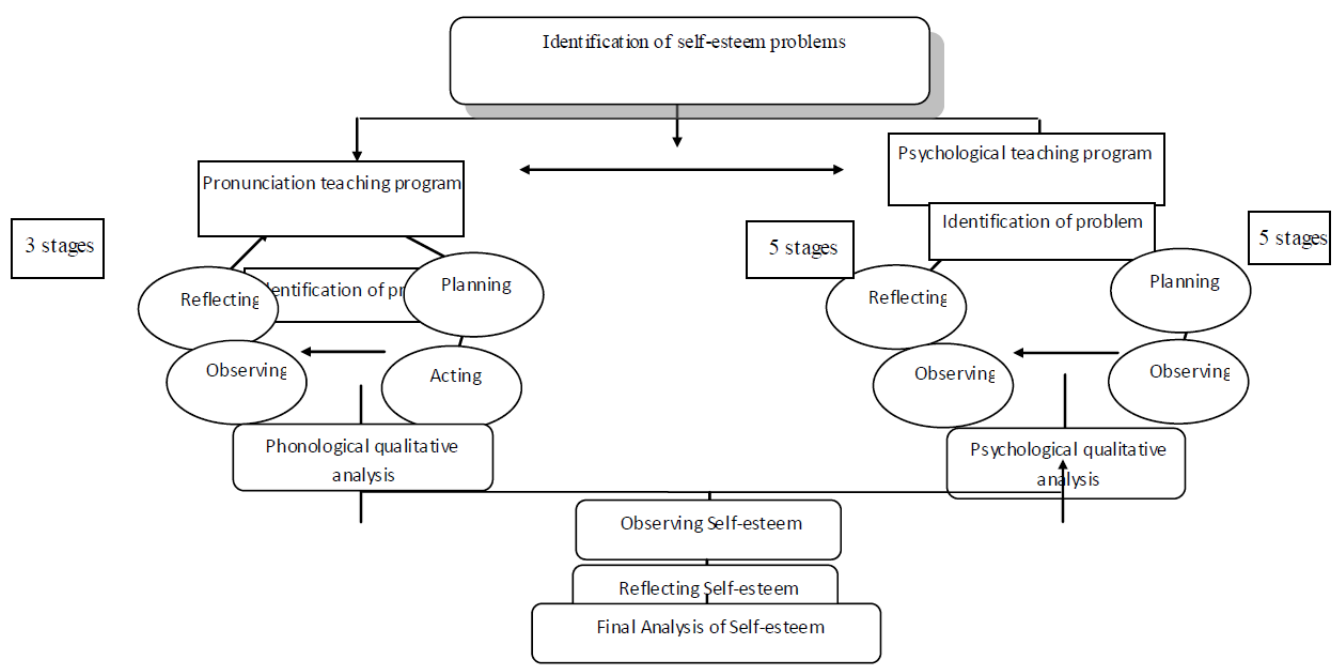

Figure 1. The Action Research Model of the Present Project

\section{CyCle ONE}

In this cycle, the main problem of the Kurdish students participating in our project detected. They appeared to have mostly unbalanced self-esteem (Bonet, 1997, Gill, 1980) when they are in class or among a group of classmates. After discussion, it was suggested that a useful way would be to devise a teaching program combined with two main branches as two complementary wings for the program namely phonological and psychological trainings, which could be usefully combined for the benefit of the students.

\section{Teaching Program}

Phase 1: Phonological teaching program

This phase contained three interrelated cycles. Each cycle had its own design beginning with planning and proceeding to acting, observing and at last reflecting. It began with the identification of some main phonological problems. The student's problems in Persian pronunciation while they were speaking Persian identified in this cycle.

Identification of the Problem

The first thing that one might feel while talking to our ten participants was their foreign accent. Their Persian pronunciation heavily affected by their native language. Perhaps they had problems with other aspects of Persian such as grammar or writing, the same as everyone who use a second language, but we thought that when speakers improved articulation and with regular practice they could improve performance and confidence (Avery\&Ehrich, 1992). Therefore, we began with their improving pronunciation. We identified each student's pronunciation problems for himself/herself specifically through their interviews and focus group discussions, which tape-recorded for each individual. For each of them we formed a pronunciation profile that showed exactly their problems in speaking.

The participants had mostly problems in the following aspects of Persian pronunciation and they mostly substitute them for their own native language. The elements of pronunciation divided into two categories:

Segmental (for accuracy): Pronunciation of the following Persian vowels $/ \mathbf{o} /, / \mathbf{a} /$ and these Persian consonants: $/ \mathrm{l} /, / \mathrm{l} /, / \mathrm{v} /, / \mathrm{h} /($ table I)

TABLE I.

PROBLEMATIC PERSIAN CONSONANTS AND VOWELS FOR THE PARTICIPANTS (IPA SYMBOLS WERE USED)

\begin{tabular}{|c|c|c|c|c|c|c|}
\hline Persian sounds & /âa / & $/ \mathrm{o} /$ & $/ 7 /($ glottal stop $)$ & $/ 1 /$ & $/ \mathrm{v} /$ & $\begin{array}{l}/ \mathrm{h} / \text { (glottal } \\
\text { fricative) }\end{array}$ \\
\hline $\begin{array}{l}\text { Sounds used } \\
\text { instead }\end{array}$ & $\begin{array}{l}\text { /æ/ } \\
\text { e.g. } \\
\text { âvâ } \longrightarrow \text { ævæ }\end{array}$ & $\begin{array}{l}\text { /u:/, /au/,/ ow/ } \\
\text { e.g. } \\
\text { xod } \rightarrow \text { xud } \\
\text { dorân } \rightarrow \text { dauran } \\
\text { dzelo } \rightarrow \text { dzelow }\end{array}$ & $\begin{array}{l}\text { § } \\
\text { (Voiced } \\
\text { pharyngeal } \\
\text { fricative ) }\end{array}$ & dark /1/ & $/ \mathrm{w} /$ & $\begin{array}{l}\hbar \\
\text { (voiceless } \\
\text { pharyngeal } \\
\text { fricative) }\end{array}$ \\
\hline
\end{tabular}

Suprasegmental (for fluency): Persian consonant clusters, stress, intonation, duration and pause

Consonant clusters. It was difficult for the students to pronounce some Persian consonant clusters. Persian syllables maybe structured as (C) V (C) (C). It means that a very common type of Persian words consist of the pattern "consonant + vowel + consonant cluster", which are pronounced as a conjunct. This structure is predictable and possibilities are CV, CVC, and CVCC. The participants showed that they are not convenient with this syllable pattern so that they tend to break syllables or blend them. Using more than one consonant as onset was not difficult for them and all of them might be influenced by their native pronunciation. There are some real examples in table II. 
TABLE II.

EXAMPLES OF DIFFERENCES BETWEEN PRONUNCIATIONS OF SOME WORDS WITH KURDISH PARTICIPANT PRONUNCIATION OF THE SAME WORDS

\begin{tabular}{|l|l|}
\hline Persian common pronunciation & Kurdish Participant pronunciation \\
\hline /PoStvâne/ & /P $\int \mathrm{tvæne/}$ \\
\hline$/$ Senâxt/ & / nnæxt/ \\
\hline$/$ bærresi/ & $/$ bresi// \\
\hline$/$ kermân $\int$ âh/ & $/$ krmæn $\int \mathfrak{~ h / ~}$ \\
\hline
\end{tabular}

In this table, the examples showed that the Persian phonotactics is not equal to their native ones. For example the cluster/ P $\int \mathrm{tv}-/$ is an impossible pronunciation before a vowel and at the beginning of a syllable. Moreover Persian speakers in pronouncing such clusters use a very short pause between $/ \mathrm{t} /$ and $/ \mathrm{v} /$ because each belongs to separate syllable.

Stress, intonation, pause and duration

The participants while talking in Persian had a foreign accent even when they could use the correct pronunciation of problematic Persian sounds and consonant clusters. From analyzing their Persian speech tape-recorded, we got to this conclusion that they should have some training in this part too. We observed that sometimes they tried a lot to imitate the Persian words as they think they are correct but they even did not think about some language elements that are not so visible but be felt (as they later mentioned). We have lot examples but just some of them can show the need for suprasegmental elements practicing:

The participants pronounced the sentence /lâzem æst/ in this way /læzmst/. This sentence consists of two words (means: need+ to be), with a pause between them. All of the participants pronounced this sentence without a pause.

\section{Planning}

We planned for a teaching program, which aimed to making improvement the participants' pronunciation beginning with some basics to the specific mistakes of an individual. For teaching program we chose different Language Learning Strategies(LLS) devised by Oxford(1990).As Oxford puts forward the points about the importance of these strategies "...because they are tools for active, self-directed involvement and are essential for developing communicative competence" (1990a, p.1). LLS along all its benefits, could contribute to the development of self-correction techniques and self-monitoring strategies.

The teaching program for pronunciation phase was devised of weekly 2 hours during two months and through three stages, each stage contains the relative themes to the participants' problems with an action design of planning, acting, observing and reflecting by itself. Some special textbooks on Persian segmental and suprasegmantal phonology selected for the stage. One of the researchers of the present study as the experienced and native instructor of Persian phonology undertook the implementation of phase one. The followed tables (III, IV, and V) show the stages of the pronunciationteaching program.

TABLE III

STAGE 1: TEACHING SEGMENTAL ASPECTS OF PERSIAN SPEECH SOUNDS

\begin{tabular}{|l|l|}
\hline \multicolumn{1}{|l}{ STAGE 1: TEACHING SEGMENTAL ASPECTS OF PERSIAN SPEECH SOUNDS } \\
\hline General objective & Stage 1: 4 sessions, 8 hours \\
\hline Specific objectives & Raising awareness toward Persian speech sounds \\
\hline Expected progressions & $\begin{array}{l}\text { - Making familiar with vocal tract, place and manner of articulation, state of vocal cords } \\
\text {-practicing the pronunciation of Persian vowels and consonants, emphasizing on the } \\
\text { participants' problems }\end{array}$ \\
\hline Activities (regarding LLS) & $\begin{array}{l}\text { Pronounce correctly each Persian sound the participants had problem with it } \\
\text { Differentiate place/manner of articulations listen to tape of native speaker and practice } \\
\text { Reflective report } \\
\text { Group discussion }\end{array}$ \\
\hline
\end{tabular}

TABLE IV

STAGE 2: TEACHING PERSIAN SYLLABIC STRUCTURE AND SOME GIVEN CONSONANT CLUSTERS

\begin{tabular}{|l|l|}
\hline Teaching syllabic aspects of Persian\& consonant clusters & Stage 2: 1 session,2 hours \\
\hline General objective & Raising awareness of Persian syllabic system \\
\hline Specific objectives & $\begin{array}{l}\text { - Making familiar with Persian syllables and its parts } \\
\text {-practicing Persian consonant clusters emphasizing on the participants' } \\
\text { problems }\end{array}$ \\
\hline Expected progressions & $\begin{array}{l}\text { Pronounce correctly each Persian consonant clusters the participants had } \\
\text { problem with it }\end{array}$ \\
\hline Activities(regarding LLS) & $\begin{array}{l}\text { Listen to tape and practice syllables, consonant clusters and words together/pair } \\
\text { works } \\
\text { Reflective report } \\
\text { Group discussion }\end{array}$ \\
\hline
\end{tabular}


TABLE V

STAGE 3: TEACHING SUPRASEGMENTAL ASPECTS OF PERSIAN

\begin{tabular}{|l|l|}
\hline Teaching Segmental aspects of Persian & Stage 3: 3 sessions,6 hours \\
\hline General objective & Raising awareness of Persian suprasegmental aspects \\
\hline Specific objectives & $\begin{array}{l}\text { - familiar with vocal tract, place and manner of articulation, state of vocal cords } \\
\text {-practicing the pronunciation of Persian vowels and consonants, emphasizing on the } \\
\text { participants' problems }\end{array}$ \\
\hline Expected progressions & Pronounce correctly each Persian sound the participants had problem with it \\
\hline Activities(regarding LLS) & $\begin{array}{l}\text { Pronounce sounds and words together/pair works } \\
\text { Differentiate place/manner of articulations } \\
\text { listen to tape of native speaker and practice } \\
\text { shadow talking } \\
\text { Reflective report } \\
\text { Group discussion }\end{array}$ \\
\hline
\end{tabular}

Phase 2: Psychological teaching program

This phase contained five interrelated cycles. Each cycle had its own design beginning with planning and proceeding to acting, observing and reflecting. It began with the identification of some main psychological problems.

Identification of the Problem

Participants of this project from the beginning showed that they are among those university students that were experiencing some challenges. They said that the new environment was very different from their own native one, this led to their confusion. For example in the first interview, one of them stated, "I cannot speak Persian well. I involved many problems from the time I arrived the University. I prefer not to speak at all in classroom and in front of others... "or another student's comment"...I feel so discomfort when my classmates mock me because of my accent. It is more safe not to communicate with others...". Or another one said;"... It is impossible to make friendship with Persian speakers because they are very different from us. I just dream of finishing my studies and back to my hometown..." Altogether, they argued that they confronted with linguistic, communicative, cultural differences and all these hindered them to concentrate satisfactorily on their school works and some of them thought that they could not continue their studies successfully. One of them said, "If I had the opportunity to continue my studies in my hometown and among other Kurds, I didn't had the problem of communication and I could study better...."

We as researchers recognized that the last above comment can be stated by any students including Persians, all the students do not like to be mocked, to be far from home, some of them are shy or depressed or having any other problem irrelevant to the way of their speaking. However, our ten selected students are those that they really had psychological problem because of a sort of inability to communicate in Persian. Then we were going to focus specifically on their problems. Moreover, we had some Kurdish students that did not felt any problem at all in spite of unintelligible Persian. However, our ten participants really were interested to overcome their Psychological problem that to us seemed to show some symptoms of low or unhealthy self-esteem.

We planned for another training program so that they can get some life skills along with overcoming pronunciation problems. It was based on a large studies literature showed that life skills help people feel confident in themselves to handle all types of social situations. Several studies showed that training life skills can result in building and increasing self-esteem(some of them: Atkins \& Jennings,1971,Atkins,1984, McNamara et.al., 1982, Wald, 1981).The students should be helped to fulfill the self-esteem need (Maslow, 1987) as the natural and psychological need for all human being namely need to respect himself/herself and through which success will be so close and tangible.

Planning

The course planned based on the life skills categories suggested by World Health Organization (WHO) in UNICEF (1993). Although there is no definitive list of life skills, the organization introduced this list as it includes the psychosocial and interpersonal skills generally considered important to produce powerful behavioral outcomes. Ten life skills concluded in three main groups as follows: Communication and Interpersonal Skills, Decision-Making and Critical Thinking Skills, Coping and Self-Management Skills. For our course, we selected some related skills among others, which we thought the students need most to be equipped. They are as follows:

1 Skills for increasing internal locus of control: Self esteem/confidence building skills; Self-awareness skills including awareness of rights, influences, values, attitudes, rights, strengths and weaknesses Goal setting skills; Selfevaluation / Self-assessment / Self-monitoring skills

2 Empathy: Ability to listen, understand another's needs and circumstances, and express that understanding

3 Interpersonal communication skills: Verbal/Nonverbal communication; Active listening; Expressing feelings; giving feedback (without blaming) and receiving feedback

4 Decision making / problem solving skills: Information gathering skills; Evaluating future consequences of present actions for self and others; Determining alternative solutions to problems; Analysis skills regarding the influence of values and attitudes of self and others on motivation

5 Skills for managing stress: Time management; Positive thinking; Relaxation techniques

The teaching program for life skills phase devised of weekly 2 hours during two months and through five stages, each dealing with one of the mentioned skills we found out the participants need. Some special textbooks on life skills selected for the stages. The other researcher of the present study as the experienced and specialized instructor of 
educational psychology undertook the implementation of phase two. Each stages of the course planned with an action design of planning, acting, observing and reflecting by itself. Table 6 is a very short summary of this very complicated course.

TABLE VI

STAGES OF TEACHING LIFE SKILLS

\begin{tabular}{|c|c|}
\hline Teaching Life Skills & 5 Stages: 9 sessions, 32 hours \\
\hline Self awareness skills & Stage 1: 2 sessions, 8 hours \\
\hline Some Specific objectives & $\begin{array}{l}\text { - Activate mind with the importance self awareness } \\
\text { - thinking more about their own characteristics } \\
\text { - making sensitive to their strengths and weaknesses } \\
\text {-introducing force group }\end{array}$ \\
\hline Activities & $\begin{array}{l}\text { Practice based on their different brainstorming\& provided situations and actions } \\
\text { Diary } \\
\text { Reflective report } \\
\text { Group discussion }\end{array}$ \\
\hline Anger Control Skills & Stage 2: 2 sessions, 8 hours \\
\hline Some Specific objectives & $\begin{array}{l}\text { - Activate mind with the Importance of anger control } \\
\text { - Awareness of the degree of own anger } \\
\text { - Practice on effective anger control }\end{array}$ \\
\hline Activities & $\begin{array}{l}\text { Practice based on their different brainstorming\& provided situations and actions } \\
\text { Diary } \\
\text { Reflective report } \\
\text { Group discussion }\end{array}$ \\
\hline Stress Control Skills & Stage 3: 2 sessions, 6 hours \\
\hline Some Specific objectives & -stress concept \\
\hline Activities & $\begin{array}{l}\text { Practice based on their different brainstorming\& provided situations and actions } \\
\text { Diary } \\
\text { Reflective report } \\
\text { Group discussion }\end{array}$ \\
\hline \multirow[t]{2}{*}{ Social\&Communicational Skills } & Stage 4: 2 sessions, 6 hours \\
\hline & $\begin{array}{l}\text { - Activate mind with the Importance of Social Communicational Skills } \\
\text { - Practice on becoming skillful in these skills } \\
\text { - Practice on becoming skillful in self-expression skills } \\
\text { - Practice on becoming skillful in saying”NO" }\end{array}$ \\
\hline \multirow[t]{2}{*}{ Activities } & $\begin{array}{l}\text { Practice based on their different brainstorming\& provided situations and actions } \\
\text { Diary } \\
\text { Reflective report } \\
\text { Group discussion }\end{array}$ \\
\hline & Stage 5: 1session,4 hours \\
\hline Problem Solving \&Decision making Skills & $\begin{array}{l}\text { - Activate mind with the importance of Problem Solving \& Decision making Skills } \\
\text { - Practice on becoming skillful in effective solving problems } \\
\text { - Practice on becoming skillful in effective decision making }\end{array}$ \\
\hline \multicolumn{2}{|l|}{ Some Specific objectives } \\
\hline Activities & $\begin{array}{l}\text { Practice based on their different brainstorming\& provided situations and actions } \\
\text { Diary } \\
\text { Reflective report } \\
\text { Group discussion }\end{array}$ \\
\hline
\end{tabular}

Based on the action design, the first cycle utilized a reflective practice framework where the participants involved an intervention (teaching programs), and they were asked to evaluate the activities thought the courses and give their feedback so that the learning strategies could be flexible and changeable according to the feed backs up to the time the goal for each stage could be gained. Then in this cycle we recognized the problems and planned for the application of different strategies to solve them namely through the training program. This cycle lasted over a period of ten months. The team (including the instructor researchers, two observers of the project) met weekly to plan the programs and in some sessions, the students were asked to evaluate the planning. The proposal of the project with its detailed planning was permitted officially by the research University authorities and its grant was determined in this cycle. The team while conducting the research accepted ethical consideration including the measures of confidentiality, consent and anonymity of the participants. The team came to this agreement that all the activities of the project must be firstly beneficial to the participants.

\section{CYCle Two AND THREE}

In this cycle, the planned programs implemented over a period of two months. The instructing team held workshops weekly for the two courses based on the arranged lessons exactly provided for each session. The teaching program then started gradually and the participants responded to it. The activities evaluated in each session by different strategies determined so that the team could modify the programs in light of feedbacks. The second cycle then focused on achieving the general and specific aims planned. 
The last cycle aimed in analyzing whether the actions done could solve or make any change to the identified problems and to what extent. The data obtained from the second cycle revealed that the teaching program was very beneficial though it needed to be more modified to meet some more satisfactory outcomes. In this cycle, we decided to disseminate some part of the main findings through the present article.

\section{Data Types, Data Collection and Analysis Data Types}

In this project, several data types elicited from three reflective sources: the researchers, the participants, the observer instructors, to get a rich understanding of the participants' self-esteem development and to examine the effectiveness the method to test the research hypothesis. Each data type can be described as follows:

Observation. The instructor researchers and the observers of the present study as two groups of specialized sources from the beginning up to the end recorded their observations for each activity. Their journals were the main data that preceded each step to the other. Through the observation of each session the instructor could decide whether the training could solve the problem or there needs to have some correction training again. After each stage done by the main instructor, the observer could check the training process to see whether the education were enough to solve or decrease the problem or still some other ways is better to be performed. Through negotiation and consensus of the mentioned sources based on the observations, many data have gained.

Reflective Reports and diaries. Participants as the main reflective sources of this research wrote a short summary of their phonological and psychological developments separately at the end of each step of the courses. They were encouraged to write carefully about the changes that they feel after got trained in some given problems that they involved in before and to reflect on how they had developed over the sessions some special issues. These reflective notes could lead the researchers to the rest of the training over the course.

Tape Recording. From the beginning when we were in identifying the problem, we recorded all the interviews. This helped us to concentrate on the real problems and to select the appropriate participants. After beginning the courses also we tape recorded all the sessions especially to check the participants changes in Persian pronunciation as well as to control the possible developments of the participants ideas in life skills. The recordings were very precious for us when we wanted to follow the course of the changes for each participant both psychologically and phonologically.

Courses Feedback. The participants' perceptions about the optimal activities in two courses of the action research project acquired through some various ways. After each of the eight stages of two courses of the project, the participants invited to focus group discussions about the same stage. They talked about the effectiveness of the materials and training and they discuss with the instructors about their views. In both courses, participants also evaluate the activities through the semester and filled the special form of evaluation the courses from different aspects regarding the instructor performance, effectiveness of the textbooks and teaching strategies, and the changes the participants could observe after this semester in themselves. The observer instructors checked and monitored different focus groups throughout the semester by themselves and at the end as well to get an overview of the right feedback.

Data Collection

Data collected from the main above-mentioned groups helped us to proceed with one stage after the other and become close to the analysis. Participant data gathered through Coopersmith's questionnaire, first focused interviews to identify the problems and continued to their different reflections( reflective reports and diaries, free text comments, group disscussion,class activities and their assignments). The researcher team gathered a lot important information from their own observation and outside observers in the form of activity reports, tape recording ,group disscussions and more important than others was the observation of this ten participants in real situations by detecting their behaviors and activities in their school classes and university environments by the help of some colleagues as their teachers and our outside observers. All the data was categorized using some main elements of the research that is teaching, practicing and researching, collaborating identified from the action research literature.

The total period of data gathering extended over a period of 8 months, 6 months before running the teaching program (lasted two months).

\section{Validation}

Measures proposed by MacTaggart (1994) to validate findings in action research could be appropriate to be utilized. These measures as Mctaggart suggest interrelations between" observations and interpretations", "participant confirmation" and "testing the coherence of presented arguments" (p. 327).

We had different sources along with different methods of data gathering. The instructor researchers and outside observers were all experts and experienced with the responsibility undertook in the project (both as applied linguists and as educational psychologist). The observations and interpretations offered by the observers after each stage in both teaching courses could be useful sources to validate the actions .Moreover some other colleagues as expert witnesses verified our planned lessons and the actions in cycle one.

Throughout the implementing the project and before that in cycle one process we did not ignored the participants' feedback as confirmation. Their feedback in focused discussions and interviews could verify the self-esteem questionnaire. As MacTaggart suggested the coherence of our arguments should be tested .We began to disseminate some part of our findings in order to implement in a practical and wider scope. 


\section{FINDINGS}

Based on the reflections of the actions done in teaching program, we had three perspectives that provided a good amount of data.

\section{a. The Participants' Perspectives}

The students as participants of the project responded both teaching programs very positively. The teaching programs according to the students' comments helped them to get an insight of respecting themselves through the trainings of the programs.

\section{Reflection on Pronunciation Program}

Several means used to get the real effectiveness of the pronunciation training from the students point of view. Their last written reports, final focused group as well as a typical quantitative questionnaire with a five Likert scale (from "weak" to "excellent") evaluating different items such as the instructor's ability to convey the material and managing the course, the effectiveness and the amount of the materials, the degree of change felt in their pronunciation and other related questions. The first specific point that they refer to was the word" awareness" of learning language:

“...This program opened a new horizon to me that I never thought about it before. Now I am aware of different aspects of Persian as well as my own native language. One should learn the points taught if he wants to speak a second language fluently..." (Student comment).

The second point they discussed on was the" improvement of pronunciation":

"...I could correct my pronunciation mistakes. Before attending this course I thought it was impossible to pronounce some words... Now I think that I can try to learn other languages easily ..." (Student comment).

The last point that elicited from their feedback was the one we really wished to namely "progression of their self confidence" that could lead to increasing self-esteem, as most of them revealed this somehow but just one idea is put forward here:

"I was ashamed of my Persian speaking in front of others, because I made mistake in stating some words so that the addressee couldn't get my point. This made me crazy and depressed. Now I am practicing and I know how to correct myself. This gives me a good feeling..." (Student comment).

“...With the information and strategies learned from this course I could correct myself confidentially..." (Student comment).

Although the participant evaluated the course positively but they complained that the period of the course regarding the tense materials, was too short. They believed that they needed more time and practice to catch the more satisfactory outcomes. In their reflections, many comments such as" I need more practice", "I am aware of my speaking mistakes but I should keep to practice" can be seen in their different reflections.

\section{Reflection on life skills Program}

The participants revealed enormous evidences as reflection to the actions of this course. "Awareness" of "the necessity of obtaining the skills in order to make a change" was among their comments. Some of their comments show the positive results of the training:

"I didn't know that I could learn to hinder my anger before. Previously I deemed that this is an innate characteristics..."(Student comment).

"...I could take advantage of the skill decision making and problem solving a lot .because we all the time are involved with this fact ..." (student comment).

The students discussed that the skills could motivate them to think and act about "changes" in their life and came to this conclusion that they are so powerful and their abilities as a human being is very valuable and considerable.

\section{b. The observers' Perspectives}

The observers' of the project were two experts on the teaching program that officially observe the different stages of the training plans. After each step of the each program the related observer examined the actions done and discussed his perspectives with the instructor to help the cycles were running in a sound movements, if some steps were misleading and violate to get the goal, he discussed it with the instructor. Some views of the last qualitative analysis of the pronunciation observer in his report are as follows:

"The analysis of data based on the three stages of the course revealed that the student felt very positive about the course and figured out a number of benefits to themselves. Teaching boosted their awareness, pronunciation as well as their confidence and gave them opportunity to speak Persian in front of other better than before."

The observer also reported some shortcomings for the course based on the data. He reported that comparing the pronunciation at the beginning and at the end of the course, the ideal changes were satisfactory but not wonderful. As he reports:

"It goes without saying that polishing the pronunciation of a second language needs a lot of practice and more time .I suggest to follow up the issue over a period to observe the effectiveness of the training."

c. The instructors' Perspectives

The role of the instructors in this research from just teaching moved to research acting as a facilitators and resource person in the management of the research process. By this project, the instructor searched for helping in solving a problem. They functioned as researchers in the collection and analysis data. Both of them searched for bigger objectives 
so that their perspectives of the instruction programs always went beyond to solving the problem of self-esteem through their trainings.

Linguist instructor

The aim of teaching phonological aspects of Persian to the participant considered to have benefits to improve Persian pronunciation to become close to some main aims. The instructor analyzed the activities done in this course effective because the feedback collected showed. The instructor reported in detail the results gained with qualitative analysis based on the reflections, here is just a summary list of it:

1. Progression of awareness toward pronunciation of a second language

2. Considerable improvement in Persian pronunciation

3. Progression of self confidence in speaking Persian

Psychologist researcher

The qualitative analysis of the instructor of life skills based on the reflections obtained from different activities. She classified the changes throughout the process as follows:

1. Progression of awareness toward each skill and in general

2. Considerable improvements in learning, using skills in everyday life and relatively become skillful on them

3. Raising motivation in utilizing skills in similar situations

4. Decreasing the previous problems

5. Increasing healthy self-esteem through acquired skills

\section{DISCUSSION}

The objective of this project was to implement and to evaluate a teaching program for non Persian Iranian University students to identify the possibility of desired change in their self-esteem. The findings suggested that the students benefited from participating the courses in practice areas that focused on practice and were taught by both a linguist and a psychologist together.

The researchers faced some limitations in this study. The facts that the study as an action research was not big in scale, the participants were just ten and the context specific teaching and researching team so small, were undeniable. The study may seem not be replicable and generalizable in some other places. Although regarding all these, researchers believe that the project could achieve some valuable results and profound effects on the students. Moreover, because the researchers were also the instructors of the study, this might lead to bias and personal subjectivity in data collection and interpretation. Although we used some devices to eliminate this effect by continuous evaluation of findings and the observers also monitored the activities continuously, but this issue still can be controversial. Furthermore the ethnolinguislic issues had always been challenging and may lead to some other challenging areas such as notion of inferiorization, linguistic rights and tolerance, language policy, cultural differences and so on that are so complicated to deal with. To avoid this also the researchers of the project tried to view the study from just an educational point of view and they viewed Persian as a second language of the participants. There need some different contexts and other related researchers to ascertain whether the teaching programs really helped the participants to make a change in their personality. Additionally we believe that the proposed model of this study can be applicable to other contexts. However, the project needs to implement a follow up program at least for one year.

Collaboration of psychology and linguistics in establishing a change also can be viewed as a limitation of the study. However, we thought that for the specific problem that we identified and for specific participants of the study this approach would be beneficial although there may be some other ways we could not find. The findings also supported this at the end and throughout each stage of the action research. All the time we confronted positive changes along with raising motivation invited us to continue. The sentence "I feel confident to speak" or "Now I know how to behave in different situations" were heard several times in our sessions and these demonstrated that the program had a positive role for this change.

The desired change of self-esteem could be observed through the last reflective reports. One of them stated "I love my own native language, But as an Iranian I love to be fluent in Persian too..." Or " I could find a lot friends now, not just among Kurds...".These are the comments of healthy and high self-esteem people demonstrated to have more confidence than low self-esteem people( McFarlin \& Blascovich, 1981, Crocker \& Park, 2004), From the beginning we planned for healthy self-esteem not just high self-esteem (Baumeister,et al., 2000; Baumeister, et al., 2003). Our participants at first focused interviews and through Coopersmiths' self-esteem test, before being aware of the purpose and process of the project tried to show off and exaggerated about their abilities. So that some demonstrated to have wrong high self-esteem, Collaboration of two courses was a good chance for them, they practically polished their Persian and at the same time gained some very important life skills that helped them to improve to get a sound position in society and by themselves. The program tried to be structured on reality and the importance of sincere Personal efforts required to build a firm base for taking on new tasks and challenges. In the course of teaching process they honestly strived to get healthy self-esteem through creating some positive changes in their actions and attitudes and we researchers also learned a lot from this program. 
The authors are grateful to the Kurdish students in participated and the observers of the project all in Vali-e-Asr University of Rafsanjan, for their help, patience and sound comments.

\section{REFERENCES}

[1] Atkins, W.R., \& Jennings, F. (1971). Development of a life skillscurriculum in community junior colleges. Junior College Research Review, 5, (9), 2-6.

[2] Atkins, W. R. (1984). Life skills education: A video-based counseling/learning delivery system. In D. Larson (Ed.) Teaching Psychological Skills: Models for giving psychology away. Monterey, CA: Brooks/Cole.

[3] Allport, G.W. (1955). Becoming: Basic considerations for a psychology of personality. New Haven: Yale University Press.

[4] Avery, P \& Ehrlich, S (1992). Teaching American English pronunciation. Oxford University Press, Oxford.

[5] Baumeister, R. F., Bushman, B. J., \& Campbell, W. K. (2000). Self-esteem, narcissism, and aggression: Does violence result from low self-esteem or from threatened egotism? Current Directions in Psychological Science, 9, 141-156.

[6] Baumeister, R. F., Campbell, J. D., Krueger, J. I., \& Vohs, K. D. (2003). Does high self-esteem cause better performance, interpersonal success, happiness, or healthier lifestyles. Psychological Science in the Publication, vol. 4, (1), 1-44.

[7] Baumeister, R. (1996). Should schools try to boost self-esteem? Beware the dark side. American Educator, 20, 14-19.

[8] Branden, N. (1969). The psychology of self-esteem. New York: Bantam.

[9] Burns, A (1999). Collaborative Action Research for English Teachers, Cambridge University Press.

[10] Bonet,J.(1997). Sé amigo de ti mismo: manual de autoestima. (Ed.) Sal Terrae. Maliaño (Cantabria, España). ISBN 978-84293-1133-4.

[11] Crocker, J., \& Park, L. E. (2004).The costly pursuit of self-esteem. Psychological Bulletin, 130(3), 392-414.

[12] DuBois, D. L. \& Flay, B. R. (2004). The healthy pursuit of self-esteem: Comment on and alternative to the Crocker and Park (2004) formulation. Psychological Bulletin, 130(3), 415-420.

[13] Eaton, J; Wardstruthers, C; Santelli, A (2006). Dispositional and state forgiveness: The role of self-esteem, need for structure, and narcissism. Personality and Individual Differences 41 (2), 371-380.

[14] Gill, J.(1980). Indispensable Self-Esteem, In Human Development, vol. 1.

[15] Greenberg, J. (2008). Understanding the vital human quest for self-esteem. Perspectives on Psychological Science, 3, 48-55.

[16] Grundy, S. (1982) Three modes of action research. In S. Kemmis and R. McTaggart (Ed.) The Action Research Reader, Geelong: Deakin University Press.

[17] Hilberg, R. S. \& Tharp, R. G. (2002). Theoretical Perspectives, Research Findings, and Classroom Implications of the Learning Styles of American Indian and Alaska Native Students [Electronic Version]. ERIC Clearinghouse on Rural Education and Small Schools. Retrieved November 27, 2006 from http://www.ericdigests.org/2003-3/alaska.htm.

[18] Kanu, Y. (2002). In their own voices: First Nations students identify some cultural mediators of their learning in the formal school system. Alberta Journal of Educational Research, 48(2), 98-119.

[19] Kemmis, S. and R. McTaggart (1988). The Action Research Planner, Third edition, Geelong: Deakin University.

[20] Kemmis, S. and McTaggart, R. (1988). The Action Research Reader. Third edition. Deakin University Press, Victoria.

[21] King, D. (1996-1997). The Effects of Cultural Differences on Self-Esteem and Learning in Students. Pennsylvania Action Research Network [PAARN] 1996-1997.

[22] McFarlin, D. B., \& Blascovich, J. (1981). Effects of self-esteem and performance feedback on future affective preferences and cognitive expectations. Journal of Personality and Social Psychology, 40, 521-531.

[23] McNamara, M \& Deane, D (1995). Self-assessment as a second language placement instrument. TESOL quarterly, 19, 673-687.

[24] McTaggart, R. (1994). Participatory action research: Issues in theory and practice. Educational Action Research. 2(3), 313-37.

[25] Maslow A. H. (1987). Motivation and Personality (3rd ed.). New York: Harper \& Row.

[26] Mecca, A. M., Smelser, N. J., \& Vasconcellos, J. (1989). The social importance of self-esteem. Berkeley, CA: University of California Press.

[27] Oxford, R. (1990a). Language learning strategies: What every teacher should know. Newbury House, Boston.

[28] Oxford, R. (2001). Language learning strategies. In R Carter and D Nunan (eds.), The Cambridge guide to teaching English to speakers of other languages. Cambridge University Press, Cambridge,166-172.

[29] Porter, J.R. \& Washington R.E.(1993). Minority Identity and Self-Esteem. Annual Review of Sociology, 19, 139-161

[30] Rogers, C. R. (1961). On becoming a person. Boston: Houghton Mifflin.

[31] Rosenberg, M. (1979). Conceiving the self. New York: Basic Books.

[32] Rosenberg, M., Simmons, R. (1972). Black and White Self-Esteem: The Urban School Child. Washington: American Sociological Association.

[33] Swanson, S. (2003). Motivating Learners in Northern Communities [Moose Factory] [Symposium: Native Literacy and Learning: Aboriginal Perspectives: Best Practices]. Canadian Journal of Native Education. 27(1), 16-25.

[34] Toulouse, P. R. (n.d). Aboriginal Self-esteem and Identity Supporting Aboriginal Student Success: Self-Esteem and Identity, A Living Teachings Approach, Laurentian University. Retrieved February 25, 2011 from http:/www.edu.gov.on.ca/eng/research/toulouse.pdf .

[35] Varasarin, P. (2007). An Action Research Study of Pronunciation Training, Language Learning Strategies and Speaking Confidence. (Unpublished Doctoral Dissertation). Victoria University, Melbourne, Australia.

[36] Wald, D. (1981). The effects of the Adkins life skills program on the employability of unemployed minority youth. (Unpublished Doctoral dissertation). New York, NY: Teachers College, Columbia University.

[37] Wallace, M.J. (2000). Action research for language teachers, Cambridge University Press, New York.

Tahereh Ahmadipour is an assistant professor in the department of language and linguistics, at Vali-e-Asr University of 
Rafsanjan,Iran.She teaches general linguistics and phonology, writing research papers in linguistics and sociolinguistics. Her published works focus mostly on sociolinguistic issues and specifically on language planning and language policy.

Somayeh Hadad Ranjbar is a lecturer of educational psychology at Vali-e-Asr University of Rafsanjan, Iran. She teaches courses in general psychology and holds life skills workshops. 